\title{
"Letter to editor" in lieu of article published in Mol Biol Rep. 2012 May; 39(5):5219-24. PTGS2 (COX2) -765G>C gene polymorphism and risk of sporadic colorectal cancer in Iranian population
}

\author{
Raju K. Mandal
}

Received: 30 April 2013/Accepted: 13 January 2014/Published online: 24 January 2014

(C) Springer Science+Business Media Dordrecht 2014

\section{Dear Editor}

Recently, I read an article with great interest published by Daraei et al., which was appeared in your journal as Daraei et al., 2012 (May; 39(5):5219-5224). The study aimed to evaluate the impact of the COX2 gene $-765 \mathrm{G}>\mathrm{C}$ polymorphism on sporadic colorectal cancer risk. Though, the study provides preliminary evidence to consider COX2 polymorphism as a risk factor for sporadic colorectal cancer. But, after careful reading of the article, few important issues came out which must be addressed for further actions.

First, it appears that the authors somehow missed the statistical power in this study. Sample sizes remain a major issue in genetic case-control studies analyzing the association of polymorphism with disease susceptibility. Hence, the study should obtain an adequate statistical power to estimate significant association accurately, which remains a primary criterion to perform such studies. Underpowered studies usually lead to false positive associations and misinterpretations [1].
The authors failed to mention the incidence rate of sporadic colorectal cancer in the said study. The number of patients and controls recruited in the present study achieved the required statistical power is questionable and did not discuss in the text. Second, in Table 2, the percentage of genotype did not reveal $100 \%$ in sporadic colorectal cancer patients. All these points suggest a thorough examination of the association observed in the said study, and must be clarified before concluding that COX2 gene polymorphism is a potential marker of sporadic colorectal cancer.

\section{Reference}

1. Hattersley AT, McCarthy MI (2005) What makes a good genetic association study? Lancet 366:1315-1323
R. K. Mandal $(\bowtie)$

College of Medicine, King Khalid University Hospital, King

Saud University, Riyadh, Kingdom of Saudi Arabia

e-mail: rajuforbiotech@gmail.com 